\title{
Educar desde la compasión. El escenario familiar como contexto*
}

\author{
Claudia Patricia Granda Ibarra** \\ Recibido: 21 de octubre de 2015 \\ Enviado a pares evaluadores: 20 de noviembre de 2015 \\ Aprobado por pares evaluadores: 22 de enero de 2016 \\ Aprobado por comité editorial: 12 de febrero de 2016
}

\section{RESUMEN}

Este artículo tiene como objetivo plantear una reflexión acerca de la educación desde la ética y la moral, centrada en el valor de la compasión como instrumento base para desarrollar otros valores altruistas, como la solidaridad, la justicia, el amor y la libertad. Con una metodología reflexiva y a partir del análisis filosófico y hermenéutico de textos y ensayos, y basado principalmente en los planteamientos de autores como Kant, Schopenhauer, Aristóteles y Mélich, el artículo pretende mostrar cómo la educación desde la compasión implica una praxis y una enseñanza desde el testimonio, con la familia como principal escenario educativo, seguido por la escuela y la sociedad, con el fin de que la persona se forme como ciudadano auténtico y autónomo, consciente de sus derechos humanos y capaz de asumir los retos del mundo presente, así como construir sus propias condiciones de vida social responsable.

Palabras clave: compasión, valor, familia, educación moral, ética.

\footnotetext{
* Artículo de reflexión producto del Proyecto de Investigación Los sentidos de familia que construyen los niños, niñas y adolescentes declarados en situación de adoptabilidad, que habitan las instituciones autorizadas para programas de adopción IAPA's, el cual es requisito indispensable para optar el título de magister en la Maestría en Educación y Desarrollo Humano de la Universidad de Manizales en convenio con la Fundación CINDE (2015).

** Abogada Universidad de Medellín. Especialista en Ciencia Política de la Universidad Nacional de Colombia. Magíster (c) en Educación y Desarrollo Humano de la Universidad de Manizales en convenio con la Fundación CINDE. Profesora de tiempo completo de la Facultad de Derecho de la Universidad de Medellín. Conciliadora del Centro de Resolución de Conflictos de la Universidad de Medellín. Abogada litigante. Correo electrónico: cpgrada@udem.edu.co; claudiagrandai@gmail.com
} 


\section{Education from Compassion. Familiar Scenario as Context.}

\section{ABSTRACT}

This article is intended to propose a reflection on the education from an ethical and moral point of view, focused on the value of compassion as a vital instrument to develop other altruistic values such as solidarity, justice, love, and liberty. With a reflexive methodology and from the philosophical and hermeneutic analysis of texts and essays, and principally according to the position of authors such as Kant, Schopenhauer, Aristotle, an Mélich, the objective of the article is to show the way education implies a praxis from the point of view of compassion and a teaching from the point of view of testimony, having family as the main educational scenario, followed by school and society, so that people can be educated as authentic and autonomous citizens, aware of their human rights and capable of assuming challenges of present time and constructing their own social conditions in a responsible manner.

Key words: Compassion; value; family; moral education; ethics. 


\section{Introducción}

El autor de este escrito no pretende sentar posición sobre las posibles maneras de solucionar los problemas epistemológicos de la educación; más bien, pretende hacer un aporte reflexivo sobre la función que tendría educar desde la compasión, entendiendo esta como valor o virtud moral suprema, que involucra otros y que se pueden identificar casi en cualquier cultura como son: la solidaridad, la justicia, el respeto por la diferencia, la tolerancia, el amor, entre otros. Con ello se apunta al desarrollo del individuo, a partir de una educación basada en el buen comportamiento moral, garantizando primordialmente condiciones de vida digna, además de promover entornos sociales y escenarios educativos con fundamentos claros en derechos humanos, y el desarrollo de sociedades que intervengan propositivamente en el respeto de estos últimos.

Al hablar de educación y especialmente de educación en valores, suele generarse un panorama de discusión entre lo que debe entenderse por educar desde lo moral y educar desde lo ético. Ciertamente, existe una creencia más o menos consecuente, sobre el mejor modelo para educar y, no obstante, las posibles diferencias que puedan presentarse en varias corrientes de pensamiento acerca del tema coinciden todas en afirmar que se educa desde unos contenidos y costumbres, permeados ambos, por normas de conducta que profesan principios y valores. En otras palabras, se transmiten unos contenidos morales, igualmente adquiridos por quienes educan, desde la tradición y la costumbre, con el objeto de que quien se educa los asimile y los incorpore en su estilo de vida.

La otra arista de la discusión radica en la prevalencia de ciertos valores, hábitos y virtudes en los procesos de aprendizaje, lo que será, en últimas, el carácter diferenciador en el modelo educativo y en su eficacia, toda vez que, dependiendo de los valores que se privilegien en la educación que se adopte, serán los resultados que se esperan.

En el presente artículo se reflexionará sobre el significado de la compasión y las implicaciones de optar por esta, como valor supremo humanizador, y como instrumento ético para el desarrollo de las diferentes capacidades de la persona, de tal manera que le permita construir sus propias condiciones de vida autónoma, propositiva, y en interacción social responsable. Los valores, desvelados en los comportamientos moralmente éticos, se encuentran presentes en la vida cotidiana; hacen parte de las culturas y, por consiguiente, de los sistemas sociales. Toda experiencia cultural y social, especialmente del orden familiar, orienta la vida de sus miembros a partir de aplicaciones de reglas morales, de conductas predeterminadas las cuales han sido previamente justificadas y aceptadas por sus integrantes, pues conciertan en que con ellas pueden forjar criterios de conducta que propicien una vida digna. Si esto es cierto, puede entonces 
procurarse desde el escenario de la familia, la institución de la compasión como valor supremo para que se convierta en una regla de conducta en el individuo, de manera que los miembros del colectivo la incorporen en sus propias acciones.

\section{Criterios de análisis e interpretación}

Los criterios considerados en el presente escrito surgieron de la lectura de varios filósofos clásicos (Aristóteles) y de la Modernidad (Kant, Schopenhauer), así como de varios doctrinantes posmodernos de las ciencias sociales y las humanidades (Ratzinger, Mélich, Duch, Uhl entre otros) con miras a un análisis reflexivo, en contexto filosófico-hermenéutico acerca del valor de la compasión en la educación, especialmente en el escenario familiar, cuando se entiende este último no solo como un escenario de cuidados, sino también educativo.

\section{Contenido}

\section{1. Ética y Moral: contenidos necesarios para educar en valores}

Concebida la ética como un saber filosófico sobre la moral, se pretende defender en este artículo que, la actividad de la educación como acontecimiento ético es, de la misma manera, una actividad moral, pues esta forma parte de la vida cotidiana tanto de los individuos como de las sociedades. A ambas se les atribuye un carácter orientador de las actuaciones humanas, máxime en los entornos sociales y/o culturales, con sus propias especificidades, las cuales realimentan sus propios "fundamentos éticos y morales".

Tanto la moral como la ética, han sido objeto de percepciones y posturas filosóficas y sociológicas totalmente disímiles. Se señala, en primer lugar, a Aristóteles. La tesis filosófica de Aristóteles parte de una perspectiva antropológica, pues centra la mirada en el hombre y en su quehacer cotidiano; aduce que el hombre, en la praxis, es actividad, afirmación que hace luego de diferenciar entre las pasiones y las acciones. Luego afirma que todo hombre inclina su acción a algún fin y una llega a éste se convierte dicho fin en el medio para otro fin que se propone. La vida del hombre entonces para Aristóteles es una cadena permanente, interminable de fines.

Sin embargo, hay un fin que es buscado por todos los seres humanos, el cual será suficiente una vez se logre; es fin último, no deviene en un medio, pues es el fin supremo de todo individuo; ese fin es la felicidad. Aristóteles igualmente señala que la praxis del hombre debe estar guiada por un valor, la prudencia, y nos lleva a convertirnos en hombres virtuosos. La virtud moral (arethé) es el resultado de la praxis, del hábito constante como hombres. Solo con la praxis, conducida por la prudencia, se llega a la arethé, a los valores morales y así se logra 
la felicidad. Esto significa entonces que el hombre no nace virtuoso, sino que se hace virtuoso, lógicamente si sus acciones son guiadas por la prudencia y la constancia, es decir, en la medida en que sea un actuar prudente y se constituya en un hábito. Pero esta arethé aristotélica no se entenderá si no se acompaña de otro elemento o concepto indispensable para comprenderla: el concepto del nosotros. En otras palabras, se piensa la ética desde el nosotros y en esa misma línea, solo se alcanza la virtud, en el diálogo con otro. Ética, para Aristóteles, es el paso del Arethé del yo, al Arethé del nosotros, de la ética subjetiva a la ética intersubjetiva en la búsqueda del valor mayor y pleno que se llama felicidad. En conclusión, desde la ética aristotélica, no hay arethé si no hay comunidad o relación con otros. Entendida así la ética desde el pensamiento aristotélico, el hombre es un sujeto moral, pues actúa de acuerdo con las costumbres, los hábitos, las acciones que realiza. El punto de quiebre y más radical está en que el hombre, al momento de decidir sus acciones, analice las consecuencias que se derivan de ellas; esto lo hace a través de la ética.

Continuando con el análisis del tema, desde la perspectiva de pensadores de la Modernidad, Emmanuel Kant (2003), por ejemplo, en su Crítica de la razón práctica, así como en la Fundamentación para una metafísica de las costumbres profesa su tesis sobre la moral y la ética. Dice Kant que "... la filosofía moral tiene que determinar con sus leyes a la voluntad humana en cuanto esta quede afectada por la naturaleza, siendo ciertamente...leyes con arreglo a las cuales todo debe suceder..." (Kant, 2002, p. 54). Parafraseándolo, toda ética debe ser formal, en su dimensión universal y racional. En este sentido un hombre actúa moralmente cuando lo hace por deber, porque es necesario, justamente, por respeto a la Ley.

Kant habla de tres tipos de acciones en el individuo: las acciones contrarias al deber, las acciones conformes al deber y, por último, las acciones por deber. La ética se enmarca en la última y, además, posee un valor moral. En su texto Fundamentación para una metafísica de las costumbres señala al respecto que

[...] Por amor a la humanidad quiero conceder que la mayoría de nuestras acciones son conformes al deber; pero si se miran de cerca sus caprichos y cavilaciones uno tropieza por doquier con ese amado yo, que siempre descuella, sobre el cual se apoya su propósito, y no sobre ese severo mandato del deber que muchas veces exigiría abnegación... acciones de las que quizá el mundo no ha dado todavía ejemplo alguno hasta la fecha, y sobre cuya viabilidad podría dudar mucho, quien todo lo basa en la experiencia, son inexcusablemente mandadas por la razón, de modo que no quepa mermar un ápice la inmaculada lealtad exigible por cada hombre en la amistad, aunque acaso hasta ahora no hubiera habido ningún amigo leal, porque este deber reside, como un deber genérico anterior a cualquier experiencia en la idea de una razón que determina a la voluntad, mediante fundamentos a priori (Kant, 2002, pp. 84-85). 
Interpretando así la filosofía kantiana, se diría entonces que la moral puede ser aprendida y asimilada por los hombres desde su vida cotidiana, condicionada al entorno que le corresponde por escenario de vida, pero sin desprenderse de su fundamento, filosófico, trascendente.

Ya en el contexto de los doctrinantes posmodernos, en las ciencias humanas y sociales, se encuentran otras posibilidades de reflexión y análisis de la ética, como la de Joan Carles Mèlich (2002) quien sostiene que la ética no es necesario trascenderla metafísicamente hablando; que bien puede hablarse de ética sin metafísica. En este contexto afirma que no es posible trasladarla a lo metafísico, pues "... la vida humana es tiempo y espacio, un tiempo espacializado y un espacio temporalizado..." (Mélich, 2002 p 25). En su texto Ética de la compasión afirma lo siguiente: "La ética surge de una situación límite, es una situación de radical excepcionalidad..." (Mélich, 2010, p. 90). Por su parte, en su obra La lógica de la crueldad, ratifica su concepto de moral en los siguientes términos: “... La moral no solo es una manera de actual sino un orden, una organización del mundo, una forma de ser en el mundo que un ser finito no puede eludir..." (Mélich, 2014, p. 46).

Cuando Joan-Carles Mélich analiza el pensamiento de Nietzsche en su texto Lógica de la crueldad, señala que para este filósofo de la Genealogía de la moral “... la lógica moral consiste en un acto de sometimiento a un principio absoluto o, en otras palabras, a un acto de vasallaje que provocará un sentimiento de culpa..." (Mélich, 2014, p. 88). A su vez, en su obra Filosofía de la finitud afirma: “... La palabra ética es hospitalaria, acogedora, y es una palabra capaz de imaginar un futuro diferente al que ella había previsto en un principio..." (Mélich, 2002, p. 22).

En este orden de ideas, continuando con el análisis reflexivo de la ética y la moral como referentes educativos y de formación en valores, juristas y filósofos del derecho, desde la Modernidad, tales como Luis Recasens Siches (1985) y Carlos Cossio (1964), sostienen que el mundo de la vida humana en sociedad se encuentra gobernado por las normas jurídicas, las normas morales y las normas de los usos o convencionalismos sociales. Hacen una clara distinción en lo que denominan mecanismos reguladores de la conducta humana que no pasan de ser juicios prescriptivos o del deber ser, los cuales señalan (no enuncian de manera causal) conductas como debidas y de cuya realización se desprende una consecuencia del orden normativo. Las normas, entonces, tanto de la moral como del derecho, pueden observarse, y con ello habrá un comportamiento justo, o pueden infringirse, para lo cual habrá una respuesta sancionatoria derivada de un comportamiento injusto.

La moral, entonces, es entendida como un compendio de pautas que dirigen la conducta humana, cuyo contenido es lo mejor y más bueno para su existencia 
plena, que fundamentalmente consiste en el cuidado de sí, pero también en el cuidado del otro.

Sea cual fuere la concepción o percepción experiencial que se tenga acerca de la moral y de la ética, en algo sí logran identidad todas las percepciones epistemológicas y/o filosóficas: el ser humano no puede abstraerse en su vida cotidiana, ni siquiera en su condición de ser social, de la moral y de la ética. Hace parte de su vida, de su entorno, bien por imposición, por extensión, por convicción o por conveniencia. Lo otro que no es posible desatender es la esencia, per se, la cual está golpada de principios, lineamientos de conducta, que para el destinatario y para el portador son buenos en sí mismos. Cuando la moral se refiere a las relaciones entre miembros de una comunidad, le corresponde a la sociedad o al grupo social, aprobar o reprochar la conducta del individuo que obra en interferencia con otro, en relación con otro, en relación de otredad y, por supuesto, imponer las sanciones, como puede ser el rechazo social, el remordimiento de conciencia o la vergüenza. En conclusión: todo comportamiento moral tiene implicaciones en el escenario social, en el contexto del grupo social en el que se reconocen los modelos y principios de conducta buena en sí misma.

Ahora bien: en lo que respecta a la educación moral, puede afirmarse que es una de las posibles maneras de lograr resultados en el proceso de formación de ciertos individuos, dirigiendo ciertas acciones educativas que propicien actitudes, comportamiento y disposiciones dentro de la vida cotidiana, de tal manera que puedan fomentarse como valores o conductas buenas en sí mismas. Se puede educar, obviamente, sin fines altruistas, sin objetivos concretos de formación en valores y comportamiento buenos en sí mismos; pero en este contexto, se trata por aportar a una educación en valores, específicamente en aquellos, dentro de los cuales se incluye la compasión, que se acerquen a un desarrollo integral del individuo.

De la misma manera que se apunta desde la Modernidad a forjar una educación integral, la cual involucra una educación moral y ética, se deben considerar aspectos problematizadores, al momento de implementar y poner en práctica dicha modalidad en educación. Esto tiene que ver con los objetivos o finalidades que se persiguen en el sujeto que se educa y los métodos que se empleen para lograrlo. Uhl (1997), en su texto Los medios de educación moral y su eficacia, señala que, a pesar de que, cada vez, la educación moral la califican como adecuada, no es fácil su implementación, pues los educadores de nuestras generaciones actuales se encuentran con dos problemas por superar. Lo dice en los siguientes términos:

[...] Muchos políticos y representantes de grupos de todas las tendencias, así como gran parte de los pedagogos, están reclamando hoy día más educación moral y, sobre 
todo, más intensiva y consecuente en las familias y en las escuelas...pero esto no es tan fácil... (que los educadores actuales) ... se hallan ante dos problemas que hacen de la educación moral algo muy difícil. El primer problema está en decidirse sobre los fines de la educación moral, y el segundo es el de la elección de los métodos educativo (Uhl, 1997, p. 14)

Pese a las dificultades o problemáticas, las teorías pedagógicas se alienan a la propuesta de la educación con fundamentos morales y éticos, que respalden la consecución y permanencia de actitudes altruistas, comportamientos que respalden valores buenos en sí mismos, no solo para el desarrollo del individuo, sino en procura de una vida cotidiana socialmente más sostenible y tolerante.

Desde esta misma perspectiva, educar desde la moral o, mejor dicho, perseguir una educación moral parece ser una situación inevitable, justamente por la tradición y la cultura que rodea nuestros escenarios de vida cotidianos. Adela Cortina, en su texto El quehacer ético afirma que “... todo ser humano se ve obligado a conducirse moralmente, porque está dotado de una estructura moral..." (Cortina, 1996, p. 80). Esta afirmación la justifica en lo que denomina la estructura moral del ser humano, sencillamente porque necesita sobrevivir y esto lo logra luego de un proceso de adaptación al medio que lo rodea; ese medio arroja posibilidades frente a las cuales el individuo se ve forzado a elegir. La moral en este entorno de análisis hace parte del medio, no lo puede eludir, no lo puede evadir, justamente porque la realidad vivida y las decisiones que se ve forzado a tomar, traerán implicaciones morales (Cortina, 1996, p. 81).

\section{La educación: actividad in-agotada y ética}

Para los fines reflexivos que persigue este artículo, la educación es entendida como un quehacer eminentemente ético y con un contenido moral definido, que para que pueda llamarse educación debe perseguir metas o fines que propicien el desarrollo integral de la persona y el reconocimiento de su autonomía y de sus derechos humanos.

Se defiende la concepción de educación como experiencia fundada en modelos de conducta y sentimientos que una persona considera sensatos y sanos y, por consiguiente, necesarios y buenos, a partir de una meta o misión, con contenidos precisos, altruistas, tales como los valores, los principios y el desarrollo humano integral (Cortina, 1996, p. 70).

Si la educación es un acontecimiento eminentemente ético, que compromete actitudes, sentimientos y criterios predeterminados de quien educa, transmitidos al destinatario de dicha educación, debemos ahondar la reflexión en el contenido de la actividad de educar, de lo que lleva consigo el acontecimiento mismo, en su contenido. Aquí entonces hablamos de los contenidos morales de 
la educación, toda vez que, si lo que pretendemos es defender la finalidad de educar desde el valor supremo de la compasión, estamos aceptando entonces que el acontecimiento de la educación lleva ínsita una moral y, de esta misma manera, una ética propia.

Uno de los logros de la Modernidad en el contexto de la pedagogía y la educación es haberle otorgado a la autonomía el carácter de fundamento importante de la actividad educativa; en este sentido, se persigue formar sujetos autónomos, con capacidad de pensar, valorar, juzgar y decidir por sí mismos. Paulo Freire en su obra Pedagogía del oprimido afirmó, a propósito de la educación liberadora que profesó en su tesis, que

[...] si pretendemos la liberación de los hombres, no podemos empezar por alienarlos o mantenerlos en la alienación. La liberación auténtica, que es la humanización en proceso, no es una cosa que deposita en los hombres. No es una palabra más, hueca, mitificante. Es praxis, que implica la acción y la reflexión de los hombres sobre el mundo para transformarlo (Freire, 1972, p. 88).

La referida educación liberadora, continúa el autor Freire en su texto

[...] ya no puede ser un el acto de depositar, de narrar, de transferir o de transmitir conocimiento y valores a los educandos, meros pacientes... sino ser un acto cognoscente... Sin esta no es posible la relación dialógica, indispensable a la cognoscibilidad de los sujetos cognoscentes, en torno del mismo sujeto cognoscible (Freire, 1972 p. 89).

Sin embargo, es preciso alinderar el concepto de autonomía, pues no se trata de una liberalidad en las actuaciones, sin ningún límite; o podríamos hablar de un libertinaje. Se trata, pues, de una autonomía fundada en valores que forjen el criterio del educando, de tal manera que defienda actitudes humanizadoras. Así, entonces, los valores que incentiven y procuren un contenido moral humanizador harán posible, como resultado, un ser humano educado desde la autonomía y la libertad responsable. Cortina (1976) aduce que

[...] es fundamental educar a los niños para la autonomía, de modo que sean capaces de pensar, juzgar y decidir por sí mismos. En definitiva, la convicción de que toda persona es un ser autónomo y que la educación se dirige a formar personas autónomas es el mejor logro de la Modernidad. (Cortina, 1976, p. 72)

Luego de hacer un recorrido por tratadistas que han servido de soporte a las reflexiones del presente artículo, se hace referencia al planteamiento que ha venido sosteniendo la UNICEF acerca de la educación cuando aduce que esta es un derecho humano fundamental, inherente a todos los niños, crucial para su desarrollo como individuos propositivos en la sociedad. La educación como actividad desarrollada en el ámbito de los derechos fundamentales contribuye a sentar los cimientos para un futuro fructífero y productivo. Sostienen esta Institución Internacional que, al garantizar el acceso a la educación de calidad, 
basada en los derechos fundamentales y la igualdad de género, se propicia una onda expansiva de oportunidades que incidirá en las generaciones venideras. Con las expectativas que se tienen en el orden internacional, para procurar una apertura a políticas homogéneas en un gran porcentaje de Estados en el orden mundial, es inminente el análisis de los métodos para, no solo lograr el acceso a una escuela (solo el instrumento) sino para que el contenido y los fines de la educación misma, aborden las debilidades que no permiten el desarrollo de algunos individuos, especialmente de niños y jóvenes, y de grupos sociales en general.

A propósito de lo sostenido por la UNICEF se destaca lo que al respecto puede rescatarse del análisis que realiza Adela Cortina en los siguientes términos:

[...] un método educativo basado en los derechos fundamentales puede abordar algunas de las desigualdades más arraigadas en la sociedad, debido a las cuales millones de menores de edad, en especial niñas, se ven condenados a una vida desprovista de una educación de calidad. La sociedad ha avanzado mucho...pero se hace mucho más énfasis en los conocimientos, en las capacidades y competencias. Se elude el papel de compromiso social como si la responsabilidad sólo se tuviera que llevar a cabo en la escuela...se ha fomentado la formación individual y competitiva y se han levantado muros de incomunicación y de exclusión (Poch \& Vicente, 2010, p. 93. Negrillas fuera del texto).

No en vano Fernando Bárcena y Joan-Carles Mélich (2000), en el análisis que realizan de la filosofía de Emmanuel Lévinas, argumentan que la educación no solo es una acción, sino que tiene, como característica fundante, la alteridad, el reconocimiento del otro, en la medida en que el ser humano tiene una responsabilidad inexcusable con el prójimo. Es así como afirman que “... con la ayuda de la obra filosófica de Emmanuel Lévinas... intentaremos caracterizar la acción educativa como una relación de alteridad, como una relación con el otro... la palabra que... me demanda una responsabilidad más allá de todo pacto y de todo contrato..." (Bárcena y Mélich, 2000 p. 126). De igual manera, destacan que la acción educativa engendra en sí misma una responsabilidad y una hospitalidad como consecuencia de la respuesta al otro la cual se fundamenta en la autonomía y en su condición de posibilidad. En estos términos lo afirman:

[...] La educación, ahora, aparecerá finalmente como una acción hospitalaria, como la acogida de un recién llegado, de un extranjero. Y desde esta respuesta al otro originaria, desde esta heteronomía que funda la autonomía del sujeto, la relación educativa surgirá ante nuestros ojos como una relación constitutivamente ética. La ética entonces, como responsabilidad y hospitalidad, no será entendida como una mera finalidad de la acción educativa, entre otras, sino por su condición de posibilidad (Bárcena y Mélich, 2000, p. 126).

De la misma manera, apoyados en las acepciones de enseñar y aprender, justamente en la línea de correlación que debe existir en la acción educativa desde 
la alteridad responsable, heterónoma y de acogida con el otro, los mencionados autores Bárcena y Mélich, en el texto que se viene analizando, aducen que en la relación educativa, el aprendizaje, más que ser una de las caras de la relación con un contenido a enseñar, es un actividad con un contenido relacional: “... En todo aprender humano se da la experiencia de un encuentro. Se aprende, sobre todo, más que un contenido, una relación... desde un trato intersubjetivo..." (Bárcena y Mélich, 2000, p. 177). Para enfatizar la afirmación sobre la influencia de la relación educativa, aducen lo siguiente:

[...] Si lo que un maestro enseña es, ante todo, una relación, es decir, su propia capacidad de apertura y de escucha, entonces sólo podemos aprender desde el compromiso con una relación. Lo importante para el aprender, es el tipo de relación educativa que establecemos (Bárcena y Mélich, 2000, p. 179).

De ahí entonces el papel que juega la imitación y el sentido que se da a lo que se aprende de la vida cotidiana.

Así las cosas, puede definirse que la educación como quehacer o acontecimiento humano, social, eminentemente ético y necesario, es “... un quehacer permanente...en razón de la inconclusión de los hombres y del devenir de la realidad..." (Freire, 1972, p. 96). Tiene reconocimiento jurídico con prevalencia de normas de conducta homogéneas a través de convenciones y tratados internacionales, los cuales la han elevado a categorías tan reconocidas como la de ser un derecho fundamental y un servicio público por excelencia. En este sentido, no hay duda de su relevancia; pero también de su carácter permeable e influyente de los ámbitos y contextos culturales, así como de lo que en ellos se vive: los valores éticos o morales, los usos, las ideologías, la religión, las costumbres, entre otros. Todos ellos tratarán de apropiarse de los sistemas, métodos y lineamientos con lo que la educación, como acontecimiento per se, repercute en el desarrollo humano y pleno del individuo. En este orden de ideas se sostiene que no puede eludirse un contenido moral o ético que identifique y, por consiguiente, realimente un método educativo, un modelo educativo, unas pedagogías educativas propias e identitarias.

\section{La compasión: ivalor o virtud?}

Siguiendo la tesis aristotélica, diríamos que un valor es un acto bueno en sí mismo el cual, con la praxis y la decisión prudente del individuo, generará un hábito que luego se convertirá en virtud. Por consiguiente, al valor es a lo que apunta la praxis prudente del hombre, tal como la generosidad, la justicia, la solidaridad. Solo se llega a ellos si hay una decisión mediada por la prudencia y por la praxis habitual. Se es justo solo si se ejercen desde la praxis acciones justas. En esta misma medida, y apuntando al valor de la compasión, se es 
compasivo, hospitalario, piadoso con los otros, si se ejercen acciones cotidianas, habituales, igualmente compasivas. Pero esta percepción no se defiende a sí misma, sin la confluencia del ejemplo, pues la praxis de un valor para que se convierta en virtud, solo proviene si está inmersa en un compendio de moralidad, respaldada por la sociedad y por quien la hace posible en su ejercicio. Es aquí donde la educación juega su mejor papel. Bien dicen Poch y Vicente (2010) al respecto que "... lo que es esencial en cualquier circunstancia es la actitud de la persona que educa, es la actitud que da confianza..." (Poch y Vicente, 2010, p. 95). En esta misma línea, Guillermo Hoyos (2004) sostiene que "la tarea del profesorado adquiere más la forma de una tarea procedimental, de gestión del conocimiento y promoción ética que la de una tarea instructiva en sentido estricto" (Hoyos, 2004, p. 25).

Ahora bien: se afirma que la ética como disciplina filosófica que reflexiona sobre la moral, buscando su universalidad, se forja igualmente desde la experiencia. Algunos pensadores como Mélich sostienen que la ética de funda desde la experiencia del mal y no del bien, tal como lo aduce en su texto Ética de la compasión en los siguientes términos: "No hay ética porque sepamos qué es el bien, sino porque hemos vivido y hemos sido testigos de la experiencia del mal" (Bárcena y Mélich, 2000, p. 222); lo vivido es la esencia, per se, de la ética, la experiencia, y con ello, la praxis en la vida cotidiana dentro de las costumbres de un grupo social.

Se considera que la compasión, para algunos, entendida como hospitalidad, piedad, misericordia, actitud de acogida, aviene con total contundencia en cualquier grupo social, con independencia de las ideologías religiosas, conductuales, filosóficas o prácticas epistemológicas. Bien lo dicen Poch y Vicente (2010):

[...] La compasión es un valor que no es exclusivo de ninguna religión ni de ninguna filosofía moral, aunque es omnipresente en el pensamiento moral de todos los tiempos, tanto en el occidente griego, romano y cristiano, como en el Oriente budista Dalai Lama o confuciano (Poch y Vicente, 2010, p. 88).

En este orden de ideas, se defiende igualmente el criterio de que la compasión, como valor moral y ético, se amolda a temporalidades y espacios: "Las definiciones... es necesario entenderlas en el tiempo y en el contexto de su época, en su contemporaneidad... pero, aun así, no pierde su vigencia" (Poch y Vicente, 2010 p 88).

En esta medida entonces, se defiende la postura ideológica de que la compasión es en sí misma un valor, que puede albergarse dentro de un entramado de normas morales y, por consiguiente, respaldadas con una convicción de una colectividad o grupo social, que se ejercerá habitualmente, generará costumbre y se afianzará en el educando, en el niño, niña o adolescente para quien va diri- 
gida la estrategia pedagógica. La compasión es un sentimiento que nos obliga a considerar el dolor y el padecimiento que sufre el otro; "nos lleva a hacernos cargo del dolor del otro y por esta razón nos sentimos impulsados a acompañarle; así la compasión es un acto de amor" (Poch y Vicente, 2010, p. 82). Así, entonces, hay un acto de desprendimiento de nuestro propio ego, pues nos olvidamos, así sea por un momento, de nosotros mismos y nos presentamos como verdaderos seres humanos, vulnerables, limitables, irrefutablemente sociales; “... en el intercambio hospitalario, se manifiesta la primera forma de una humanidad general..." (Poch y Vicente, 2010, p. 83).

\section{Educar desde el valor de la compasión}

Para nadie es un secreto que hasta en el tema de la jerarquía y de los valores mismos, se han presentado cambios en la Contemporaneidad. Pensadores del tema como Siegfried Uhl ya se han hecho esta pregunta, en el sentido de que los padres y los educadores hoy en día, se tornan indecisos al momento de proponer las virtudes sobre las cuales van a sentar su educación moral; esto, ante lo que el escritor denomina "el pluralismo de cosmovisiones y sistema morales" (Uhl, 1997, p. 16). De la misma manera aduce el autor que "la inseguridad de los adultos repercute en la educación", trayendo a colación a Brenizka (1993), y se nota más, en los fines u objetivos de la educación misma

Justamente porque el tema de los valores es objeto de manipulación ideológica, dependiendo de lo temporal y lo espacial, de la vida cotidiana, las condiciones personales y el contexto social, hay que precisar desde qué perspectiva se habla acerca de los valores, sin dudar que en la Posmodernidad hay algunos que son coincidentes, como el placer, la felicidad, la singularidad, la independencia. Sin embargo, luego del planteamiento que se realizó sobre los valores morales en otras líneas de este artículo, coincidimos con otros que denominaríamos universales, sin tiempo y sin espacio, pues son aquellos buenos en sí mismos y que llevan a la felicidad plena del ser humano, como son la justicia, el bienestar, la autonomía, la dignidad humana, la libertad, la generosidad, la solidaridad, la tolerancia, el orden social, el altruismo. Nuestra perspectiva es eminentemente propositiva, por consiguiente, subjetiva, pues lo que se propone es defender la idea de educar desde el valor de la compasión, aunque sin duda es necesario exponer una perspectiva descriptiva de la compasión (no se puede hablar de valores sino es desde un plano subjetivo, pues indubitablemente se permea la experiencia, percepción, idea y vivencia de quien lo profesa, del emisor), como valor autónomo, meta-valor, altruista, que deviene en la posibilidad de desarrollar otros valores igualmente altruistas tales como la solidaridad, la generosidad, la ayuda mutua, el reconocimiento de la diferencia, la tolerancia, la acogida, el orden social. 
Siguiendo entonces la misma línea de reflexión, se defiende el criterio de que educar en valores es participar en un auténtico proceso de desarrollo y construcción personal. Crear condiciones pedagógicas y sociales para que dicha construcción se lleve a cabo de una forma óptima. Educar en valores es poner en práctica y articular las relaciones sociales desde la moral, política y el derecho. Es un proceso complejo de formación en una cultura precisa que, para nuestra época, se contextualiza en un escenario globalizado, pero, asimismo, con profundas necesidades de reconocimiento de la ciudadanía, el pluralismo, la democracia como estilo de vida y el respeto por los derechos humanos y la solidaridad. Educar en valores hoy es formar ciudadanos auténticos que sepan asumir conscientemente los retos de la globalización y puedan comprometerse en la construcción de un mundo más justo, inclusivo, equilibrado e intercultural.

Hoyos (2004) aduce que

Educar en valores, en la ciudadanía y en y para la democracia es una cuestión de compromiso... no es pues, enseñar valores, sino, sobre todo cultiva todo aquello que hace posible que los valores, en los que seguramente tod9os coincidimos, solidaridad, justicia, libertad, honestidad, etc., estén guiados por el valor de la dignidad y, por tanto, esta esté garantizada social, económica cultural, legal y políticamente (Hoyos, 2004, pp. 31-32).

\section{La familia; primer escenario para educar en valores}

Para los objetivos de reflexión y análisis de este artículo, entendemos la familia como escenario que educa por excelencia; por lo mismo, la familia que educa desde concepciones morales y éticas definidas, especialmente desde los aportados por los valores altruistas, el desarrollo de la autonomía, la integralidad, la libertad responsable y la dignidad humana, se constituye en un núcleo de formación y de aprendizaje primario, con fines específicos de transformación propositiva de la sociedad, difícil de sustituir.

Es cotidiano que se afirme, erróneamente, que la escuela y, por consiguiente, los educadores son los responsables de la educación en valores. Se sostiene el criterio de que la Familia es el primer escenario que propicia el aprendizaje, en palabras de Hannah Arendt, desde lo privado; la escuela y los otros espacios o ambientes educativos lo serán en lo público. Hoyos (2004) dice al respecto que "educar en valores no puede ser tarea exclusiva del profesorado ni de la escuela" (Hoyos, 2004, p. 31).

En el contexto de este artículo, se entiende que la función educadora es la función primordial de la familia. En este sentido, el entorno familiar busca preparar a los niños para la edad adulta, para su desempeño en escenarios culturales, el aprendizaje de un lenguaje identitario y, por consiguiente, una 
transmisión e influencia cultural. La familia se concibe entonces, como escenario de aprendizaje de las condiciones primarias que un niño requiere para su desarrollo humano, en perspectiva futura, social y cultural, aceptable. La educación es un proceso de formación en sí mismo, que comienza siendo impartida por la familia y luego por la escuela y se necesita de ambas partes para conseguir un pleno desarrollo educativo y personal del niño o del adolescente.

A propósito del papel de la familia en el proceso educativo y, en todo caso, en la transformación social, escritores latinoamericanos de las ciencias sociales han coincidido en lo siguiente:

Instituciones como la escuela, la familia, la religión, la política, y los sistemas de comunicaciones, configuran sus propios lenguajes, crean relaciones y realidades que se entrecruzan y también se diferencian. Todas aquellas relaciones que ocurren en la vida cotidiana, relaciones familiares, relaciones entre diversos grupos, entre diversas naciones, relaciones económicas, relaciones políticas, etc., son susceptibles de un estudio y de un análisis científico (Ortiz, Ayala, Chaparro, Sarmiento \& Restrepo, 2007, p. 65).

Por su parte, la Corporación de amor al niño-Cariño-refiere la participación relevante de la familia en la crianza, educación y formación de los hijos. En su propuesta denominada crianza con cariño, se ha transmitido su compromiso como institución, en los procesos de concienciación para el cambio de los modelos de crianza y cuidado de los niños y de los adolescentes. Desde la Junta Directiva de esta institución, se apuesta por la siguiente propuesta:

Se ha planteado la educación como elemento básico en el proceso de desarrollo del ser humano, no lo es menos el proceso de formación que se tiene que dar, y una vez más, la participación que la familia tiene en el mismo. En el hogar se dan las primeras bases, los ejemplos y las pautas que determinarán futuros comportamientos de los individuos (Cuervo, 2007, p. 29).

\section{Reflexión-conclusión}

La personalidad humana deriva sus aprendizajes, por lo general, de la experiencia y la observación de lo que le acontece en su entorno; se podría decir, en términos más coloquiales, que se aprende del ejemplo. De la misma manera podríamos afirmar que la inmensa mayoría de los aprendizajes de un sujeto no se dan desde la formalidad consciente, previamente planeada y controlada por pedagogías específicas; contrario a lo que la mayoría cree, los aprendizajes del sujeto devienen de modo casual, sin plan preestablecido. Más bien se diría que los ambientes educativos en los que se tienen experiencias de vida, las cuales terminan forjando una personalidad humana concreta y definida, ofrecen oportunidades de aprendizaje. En este contexto, sin demeritar otras fuentes de la personalidad del ser humano como son las disposiciones hereditarias y su propio carácter innato, las experiencias y los entornos propician ámbitos para 
la construcción y el desarrollo del carácter y la personalidad. De la mano de los ambientes educativos y las experiencias de vida, al hombre se le facilitan los aprendizajes, por su perceptibilidad natural, su maleabilidad, su adaptabilidad. Sumando los dos aspectos, podríamos entonces concluir que, "la mayoría de las características del ser humano están condicionadas a su ambiente y a sus experiencias" (Cortina, 1996, p. 185).

En nuestro entorno cultural, se espera que el proyecto de vida de los niños y adolescentes, se constituya en el fundamento o base para que sean educados a partir de valores como la tolerancia, el auto-reconocimiento y el reconocimiento del otro, la solidaridad, el espíritu de servicio, la libertad responsable y, por supuesto, la compasión. Asimismo, se tiene la esperanza de que un proyecto de vida, amparado en valores altruistas, se construya dentro de un contexto familiar. En el caso de niños y adolescentes que no cuentan con un núcleo familiar, surge y se pone en ejecución el deber del Estado y de sus entidades protectoras de la familia y de los derechos de los niños, niñas y adolescentes, los cuales, se espera que dispongan de espacios que permitan ambientes educativos, transmisores de estilos de vida basados en valores. De ahí que no solo a los padres como educadores primarios, se les carga la responsabilidad de educar, sino en general a la sociedad, pues todos somos cuidadores y transmisores de cultura.

En este orden de ideas se sostiene que si los entornos en los cuales transcurre la vida de niños y adolescentes, especialmente el escenario familiar, encaminan hábitos y comportamientos en pro del desarrollo humano, la compasión como valor moral supremo, como sentimiento de reconocimiento del otro desde su identidad en el dolor y el sufrimiento en correlación responsable, bien puede pensarse como acción dirigida y constante en el entorno de relación con los demás, lo cual haría posible que se desarrollen otros valores correlativos a este como la solidaridad, la justicia y el amor. Es aquí donde las virtudes devienen de acciones constantes en pro de la conservación y la dignidad del ser humano (buenos en sí mismos en términos kantianos); acciones que desde la repetición ejemplificante llevarían a extenderse a quienes tenemos el deber moral de educar en pro de una sociedad responsable, sostenible y precursora del bienestar del individuo y de la sociedad.

\section{Referencias bibliográficas}

Bárcena, F., \& Mélich, J. C. (2000). La educación como acontecimiento ético. Barcelona: Paidós.

Corte Constitucional Colombiana 28 de abril de 2011. Sentencia, T-306/11.

Cortina, A. (1996). El quehacer ético. Guía para la educación moral. Madrid, España: Santillana. Colección Aula XXI.

Cossio, C. (1964). La teoría egológica del derecho y el concepto jurídico de libertad (2. a edición ed.). 
Buenos Aires: Abeledo Perrot.

Cuervo Duque, L. E. (2007). Corporación de amor al niño cariño. Antioquia, Colombia: Imprenta Departamental de Antioquia.

Freire, P. (1972). Pedagogía del oprimido. Buenos Aires: Siglo XXI Editores.

Hoyos, G. (2004). ¿Qué significa educar en valores hoy? Barcelona: Ediciones Octaedro.

Kant, E. (2003). Crítica de la razón práctica. Buenos Aires: Losada S. A.

Kant, E. (2002). Fundamentación para una metafísica de las costumbres. Madrid: Alianza Editorial.

Mélich, J. C. (2002). Filosofía de la finitud. Barcelona: Herder.

Mélich, J. C. (2010). La ética de la compasión. Barcelona: Herder.

Mélich, J. C. (2014). La lógica de la crueldad. Barcelona: Herder.

Ortiz, J. G., Ayala, C. A., Chaparro, J., Sarmiento, J. L. \& Restrepo, G. (2007). Fundamentación conceptual Área de Ciencias Sociales. Bogotá, D. C.: Instituto Colombiano para el Fomento de la Educación Superior, ICFES. Disponible en http://www.icfes.gov.co/index.php?option=com _docman\&task $=$ doc $\_$view\&gid $=1193$

Poch, C., \& Vicente, A. (2010). La acogida y la compasión: acompañar al otro. En: Márgenes de la moral. Una mirada ética a la Educación. Barcelona: Graó.

Recasens Siches, L. (1985). Introducción al derecho. México: Porrúa.

Robles, L. A. (1906). Introducción a la filosofía de la moral y las ciencias políticas. Bogotá: Universidad Republicana.

Schopenhauer, A. (2013). Arte de buen vivir. Madrid: Biblioteca Edaf.

Siegfred, U. (1997). Los medios de educación moral y su eficacia. Barcelona: Herder.

Tugendhat, E. (1997). Lecciones de ética. Barcelona: Gedisa. 